\title{
Effects of Terrorism on Children: Psychosocial Biological Understanding
}

\author{
M. Basheer Ahmed, MD \\ Fort Worth, Texas
}

\begin{abstract}
:
Terrorism, politically motivated violence directed against noncombatants, is a common occurrence globally. Thousands of children are exposed to trauma and life-threatening situations, and no child is immune to the traumatic effects of terrorism, whether they live in Oklahoma, Bosnia, Iraq, New York, Lebanon, Rwanda, Israel, Palestine, or Dar Fur. They suffer long-term psychological consequences of the trauma. Few research studies have been published addressing the short-term and long-term effect of terrorism on children. Of the studies done, most are on children exposed to trauma in Western countries. Unfortunately, research studies reflecting the experiences of severe trauma and long-term consequences of atrocities on children in the non-Western part of the world are rarely reported in scientific journals or even in media, as if the children who did not die during the terrorist acts do not exist. This article will summarize the research work on diagnoses and treatment of post-traumatic stress disorder, which is often present in children exposed to trauma and severe life-threatening situations. Special attention is paid to the effects of terrorism on children in Bosnia, Israel, and Palestine.
\end{abstract}

Key words: Terrorism, children, post-traumatic stress syndrome, depression, suicide.

Introduction

$\mathrm{M}$ any children are exposed to trauma and lifethreatening situations. During the last few decades, thousands of children have been exposed to terrorism. No child is immune to the traumatic effects of terrorism, whether they are in Oklahoma, New York, Bosnia, Israel, Palestine, Iraq, Lebanon, Rwanda, Kashmir, or Darfur.

Dr. Ahmed is in private practice psychiatry and is a former professor of psychiatry at Southwestern Medical school. Correspondence should be directed to

Dr. M. Basheer Ahmed

10 Homeplace Court

Arlington, Texas 76016

Email:mbahmed03@hotmail.com
Millions of children of the world learn about terrorist acts through watching television, but thousands of Muslim children in Iraq and Palestine watch the terror daily and have firsthand experience with severe and traumatic incidents. For example, children saw bombs destroying buildings killing scores of women and children in Lebanon in July and August 2006. The experience of the severe trauma and long-term consequences of these atrocities in children are rarely reported in the media, as if these children who did not die during the terrorist act do not exist.

Who can shield these children from such horror, and who speaks for their psychological trauma and well being? Many children end up in hospitals with limited facilities for physical care with absolutely no mental health services or psychological support. 
Thousands of children end up in refugee camps and shelters with limited resources. Food and medicine remain the top priorities in the affected area. Meanwhile, the emotional health of these traumatized children is neglected, and they live with fear, apprehension, and anger for years to come.

There are no scientific reports published on the effect of terrorism on the children of Iraq. ${ }^{a}$ Few reports were published on the effect of terrorism on Palestinian children. Several reports were published on the effects of the terrorist bombing of the Federal Building in Oklahoma City and the World Trade Center in New York. Most of the reports discuss the effect of acts of terrorism when children watch death and destruction on television. However, there is a general consensus that the disasters in which harm is inflicted intentionally, such as terrorism on civilians, are associated with higher levels of distress. ${ }^{1}$

Terrorism causes psychological trauma that results in helplessness in the face of intolerable danger and anxiety. Most of the children will suffer from post-traumatic stress disorder (PTSD), which affects cognition, emotions, interpersonal relations, and personality development. The most common effect is an enduring sense of pessimism with depression and suicidal ideations. The symptoms of depression and anger are much higher in children who more frequently experience terror, as in Palestine and Iraq. On average, every Palestinian child has witnessed about 10 traumatic incidents. Traumatized children show a range of symptoms including insomnia, nightmares, hypervigilance, and severe agitation. ${ }^{2}$ Children with adverse stress reactions and behavioral symptoms for longer than one month may be at increased risk of developing PTSD or violent and delinquent behavior later in life.,34

This article will summarize the research on diagnostic criteria for PTSD in children and adolescents and the neurobiology of early life stresses and posttraumatic disorders. It will also examine the shortterm and long-term effect of exposure to terrorism in children and some treatment modalities.

Stress of trauma is experienced when an individual (a child or adult) is confronted with a situation

aThe April 15, 2007, issue of USA Today published an article entitled "Trauma Severe for Iraqi Children", which referenced a yet-to-be-published survey conducted by Mohammed Al-Aboudi of the Iraqi Ministry of Health. that is personally threatening to self or others. Some of these children who have endured trauma will grow up with adequate coping mechanisms, but the majority, unless early therapeutic intervention is provided, will develop long-term consequences of these earlylife stresses, resulting in deep-seated psychological problems.

The diagnostic criteria for acute stress disorder and post-traumatic stress disorder are derived from studies of effects of trauma on adults. Psychological trauma and life-threatening situations may produce different symptoms in children and adolescents than in adults. In recent years, research has been done on the effects of trauma on children and adolescents. The American Academy of Child and Adolescent Psychiatry has written modified diagnostic criteria for PTSD in children and adolescents. However, shortterm and long-term effects of acute and long-term psychological trauma due to terrorism on children need to be further investigated.

\section{Early Life Experiences and PTSD}

It is now established that stress caused by emotional trauma during early development permanently affects the brain circuits critically involved in the regulation of stress and emotions. These biological scars then lead to altered behavioral and physiological responsiveness to the environment, which ultimately increases the likelihood of adult psychopathology. It appears that the neurobiological effects of early life stress may represent priming for the development of PTSD in response to subsequent stresses. ${ }^{5}$ Children who are exposed to early childhood traumatic experiences become vulnerable and are at greater risk for developing PTSD. ${ }^{6}$

According to the Diagnostic Statistical Manual, DSM-IV, the characteristic symptoms of acute stress disorder, such as anxiety, dissociation, and other symptoms, may develop within days to four weeks after the exposure to extremely traumatic stressors, such as threatened death or serious injury to self and others. The person's response includes fear, horror, hopelessness, numbness, detachment, or absence of emotional responsiveness, depersonalization, dissociation, and amnesia (unable to recall an important aspect of trauma). The traumatic event is usually reexperienced in recurrent images, thoughts, dreams, flashback episodes, or in serial reliving of the experiences. Symptoms may also include increased arousal 
(difficulty in sleeping, irritability, poor concentration, and restlessness) and avoidance of stimuli that arouse recollection of the trauma. If these symptoms persist beyond four weeks, the diagnosis of PTSD should be considered. The individual may feel guilty for surviving when others have not survived and may feel responsible for the consequences of the trauma. Symptoms of depression, despair, and hopelessness may be persistent and severe enough to meet the criteria of major depression. These individuals are at high risk for development of PTSD, impulsive, and risk-taking behavior. ${ }^{7}$

\section{Neurobiology of Early Life Stresses and PTSD}

Heim et al discussed in detail the neurobiology of early life experiences. Some regions of the brain may be particularly sensitive to adverse experiences that may lead to major and sometimes irreversible abnormalities. The stress response includes activation of the two major outflow systems, the sympathetic division of the autonomic nervous system and the hypothalamic-pituitary adrenal axis (HPA). 5

Sympathetic activation results in increased release of norepinephrine and changes in the blood flow to the medial temporal lobes and the orbitofrontal cortex during symptom provocation that is confirmed by positron emission tomography (PET) imaging. ${ }^{8}$ These brain areas are also involved in emotional processing.

\section{HPA Axis Dysregulation}

DeBellis described the biological and physiological changes in children with PTSD. Elevated levels of dopamine, norepinephrine, and free cortisol in 24hour urine specimens were found in children exposed to trauma. The urine catechilamine and free cortisol concentration were positively correlated with the duration of trauma and symptoms' severity. $9,10 \mathrm{~A}$ significantly elevated salivary cortisol level is also found in a majority of children with PTSD, especially girls. ${ }^{11}$ The increased secretion of glucocorticoids from the adrenal cortex affects the metabolism, the immune system, and the brain. These physiological changes are associated with behavioral changes such as fear, anxiety, and sleep disturbance, as well as fight and flight behavior. The preeminent neurotransmitter that coordinates these various stress response elements into one coping reaction is corticotopinreleasing factor (CRF), which causes alteration of diurnal cycles of cortisol and altered peripheral cate- cholamine levels. Abnormalities in brain electrical activity detected on electroencephalogram (EEG) were also noted, which are indicative of changes in cognitive processing of emotional stimuli and structural brain development. ${ }^{12}$

One of the recognized functions of the hippocampus is converting short-term memories into longterm associations. The hippocampus is also involved in the control of the HPA axis, in explicit memory and in contextual aspects of fear conditioning. ${ }^{13}$ Specific changes in the hippocampus are becoming hallmarks of PTSD. Traumatic stress releases glucocoticoid, which binds to hippocampal cells and inhibits their normal memory functioning. Repeated application of stress hormones may cause cellular damage in the hippocampus. Postmortem inspection of the hippocampus of patients with PTSD showed overall shrinkage caused by specific areas of atrophy. Magnetic resonance imaging (MRI) of patients with PTSD shows similar changes in the hippocampus. Medina pointed out that this data could also be interpreted to mean that patients who suffer from PTSD may have an atrophied hippocampus, and the traumatic experiences may result in the experiencing of PTSD symptoms. ${ }^{14}$ Other MRI studies found attenuation in frontal lobe asymmetry and a smaller total brain and cerebral volume. The apparent changes in brain architecture and metabolism may have functional implications. Children with PTSD have been found to perform more poorly than control subjects on measures of attention, abstract reasoning, and executive functioning. ${ }^{15}$

\section{Diagnostic Criteria for PTSD}

According to DSM-IV, PTSD in children has a different presentation and expression of symptoms than in adults. A child's response to stressful events may be expressed as disorganized or agitated behavior instead of intense fear, feelings of helplessness, or horror. Children re-experience or express the traumatic event or aspects of it through repetitive play. Children's dreams may be frightening but without recognizable content, or they may change into generalized nightmares of monsters, of rescuing others, or of threats to self or others. These children tend to have more psychosomatic symptoms. ${ }^{7}$ It needs to be mentioned that PTSD symptoms vary at different ages and different developmental stages. The American Academy of Child and Adolescent Psychiatry's guidelines for assessing and treating 
PTSD describes these symptomatic changes. ${ }^{16}$ According to these guidelines, young children may have recurrent recollection, post-traumatic play or play re-enactment, nightmares, and episodes of objective features of a flashback or dissociation. Children may also show constriction of play, social withdrawal and a restricted range of affect and loss of acquired developmental skills (especially language and toilet training). As hyperarousal symptoms in adults, children may express night terrors, difficulty in going to sleep, night awakening, decreased concentration, hypervigilance, and exaggerated startle responses. Children may manifest different symptoms than they manifest initially, including aggression, separation anxiety, fear of darkness, and new fears not related to trauma. ${ }^{15,17}$

\section{Stages of Children's Response to Disaster}

Most children respond to the trauma associated with terror in two stages. The first stage immediately after the disaster includes reactions of fright, disbelief, denial, grief, and feelings of relief if loved ones have not been harmed. ${ }^{1}$ A great deal of altruism is often displayed by children trying to help in the aftermath of such tragedies; this may help them develop resilience and also may be a marker of resilience. ${ }^{18}$ The second stage occurs a few days to several weeks after the disaster and is characterized by developmental regression in many children and manifestations of emotional distress such as anxiety, fear, sadness, depressive symptoms, hostility, aggressive behavior towards others, apathy, withdrawal, sleep disturbance, somatization, pessimistic thoughts of the future, and play demonstrating themes related to the traumatic event.1,19

The response of younger children to disaster is dominated by mood, anxiety, and behavioral symptoms. ${ }^{20}$ Younger children are not able to understand the intentions and logic of others and have great difficulty distinguishing a deliberate action from an unintentional incident. Although infants and toddlers may have no cognitive comprehension of a disaster, the loss of loved ones can lead to regression and detachment. ${ }^{1}$ Such an experience can manifest as increased crying and irritability and separation anxiety. ${ }^{21}$ School-aged children often demonstrate the experience of trauma through play expressing trauma-related themes and aggressive behavior. Older school children have greater capacity of social cognition and empathy. They tend to display more empa- thy for families who are affected by the crisis. They have greater capacity to understand why the tragedy occurred and focus more on the safety of the society as a whole. ${ }^{3,22}$

\section{Depression and Suicide in Children Exposed to Trauma}

Based on data collected in the United States, it was found that PTSD occurs in 1-4\% of the general population of children exposed to violence, trauma, or abuse. ${ }^{23}$ Foy et al reviewed 25 studies on PTSD children and found that three factors appeared to mediate the development of PTSD in children: the severity of trauma exposure, trauma related to parental distress, and temporal proximity to the traumatic events. ${ }^{24}$

Traumatized children who require therapy for PTSD have been victims of chronic and multiple terror, rather than motor vehicle accidents, natural disasters, or isolated acts of terrorism. Symptoms of depression, despair and hopelessness may be persistent and result in prolonged depression in these children.

Children and adolescents with traumatic grief are four times more likely to have suicidal thoughts. According to a study by Davidson, 19\% of PTSD patients may ultimately commit suicide. The effect of the violent death of significant others such as parents and siblings predicted a worse long-term outlook. These children have more frequent re-experiencing of trauma and more disruption in their ability to attend school and participate in structured activities. Some children experience extreme anger, and when anger is mixed with suicidal thoughts, their acts become unpredictable. ${ }^{25}$ In some cases, adolescents with depression and anger may be prepared to die (by committing suicide) while killing others for the sake of their country.

\section{Intergenerational Effects of Terrorism}

Portney summarized some of the studies of children whose parents suffered prolonged trauma in Germany, due to Nazi atrocities. The parents were the survivors of the Holocaust who were exposed to prolonged traumatic stress. These parents constantly reexperienced the torture and developed emotional numbing, which did not help the child in developing a reasonable sense of safety and predictability in the world. These parents have difficulty in modeling a healthy sense of identity, autonomy, and maintaining 
a balanced perspective when life challenges arise. Instead, they model catastrophic or inappropriately numb and dissociate responses. The parents' higher level of anxiety interfered with child development and emotional maturity. Thus, the prolonged psychological effect of trauma is passed on to the new generation. ${ }^{26}$ The suicide bombings in Israel by Palestinian militants and the aggressive strikes on Palestinians by the Israeli military will produce intergenerational anger and hatred, which may last for years, in both Israelis and Palestinians.

Although children from many parts of the world have been exposed to acts of severe violence, this article specifically examines the studies and observations on short-term and long-term effects of exposure to terrorism on children of Bosnia, Israel, and Palestine.

\section{Effects of Terrorism on Bosnian Children}

Dr. Arshad Husain, in his book "Hope for the Children: Lessons from Bosnia", elaborated on experiences of Bosnian children who faced death and destruction during the Serbian attacks on Bosnia during the mid-90s. Dr. Husain found several unusual symptoms in the children who survived the massacres. Some children were afraid of light rather than darkness as light meant snipers could see and kill them. Some children experienced the symptoms of PTSD almost every night. Children woke up in the middle of the night in terror and hid in basements. Some children woke up with any noise that reminded them of shootings. Seventy percent of the Bosnian children had seen their parents or close relatives killed, and these children had developed distressing symptoms of depression, low self-esteem, insomnia, and guilt. Some even expressed suicidal ideas saying: "I should have been dead before my mother." Forty percent of children with PTSD showed all three types of symptoms: re-experiencing, avoidance, and hyperarousal. Sometimes the children become confused and lose the ability to feel and express emotions such as "I feel so empty, sometimes I feel I am not alive. I am just here." Some children give up their childhood and act like adults. For example, a 7-year-old said, "We have to be strong and work hard for our country." 27

\section{Effects of Terrorism on Israeli Children}

Children in Israel have been exposed to suicide bombings for years. Dr. Kaplan of the Beth Sheva
Mental Health Center in Israel has extensive experience studying the post-traumatic effects on Israeli children. Exposure to terror in Israel occurs as a victim, witness, relative, or friend of the victim. Most mental health professionals in Israel are trained to identify post-traumatic symptoms in children more rapidly than in other countries and refer these children to one of five post-traumatic centers where biomedical, psychotherapeutic, familial, and socio/occupational rehabilitation programs are available. ${ }^{28}$

\section{Effects of Terrorism on Palestinian Children}

The author recently met a delegation of Palestinian mental health professionals visiting the United States. Their visit was arranged by the U.S. State Department to study treatment strategies for children with PTSD. Most of the information I am presenting is based on information given to me by Palestinian mental health professionals. Some information is also gathered from the reports published in the press. Very few research studies on the psychological effects of trauma on Palestinian children have been published.

Shafiq Masalha, a Palestinian psychologist, studied psychological consequences of prolonged trauma on 114 Palestinian children. He studied the dreams of children (9- and 10-year-olds) to measure the psychological state of the children. Seventy-nine percent of Palestinian children dreamed constantly about political violence, and $13 \%$ dreamed that they were killed or were sacrificing their own lives. These children were preoccupied with death in one form or another. These dreams and preoccupations with the violence ultimately resulted in the expression of violent behavior. ${ }^{29}$ Mahmud Sehwail, a Palestinian psychiatrist, stated that Palestinian children do not suffer from post-traumatic stress disorder, but they suffer from continuing traumatic stress disorder. In the U.S. and other countries, a person usually experiences one traumatic event and later lives in at least a protected environment. In Palestine, children are not living in a protected environment. The situation is always unpredictable. They cannot even plan for the evening or the next day. ${ }^{29}$

The most significant experiences the Palestinian children have are of intense fear, helplessness, and horror. Some young children become agitated and do not want to be left alone. They cling to their mothers or surviving relatives. These children have difficulty 
sleeping at night. They wake up in the middle of the night with nightmares and frightening dreams, without recalling the contents. Even after the withdrawal of the Israeli army, they continued to live in a state of fear that, at any moment, big Israeli tanks will return and they will be crushed. Mothers reassure the children that they are safe but they also give a realistic explanation that, if something happens to them, they will go to heaven and have eternal peace. Most of these parents were exposed to terror themselves and, therefore, suffer from PTSD and have extreme difficulty reassuring their children. Children are even afraid to go outside during the daytime or peep through windows due to the fear that the Israeli soldiers might shoot them. They are afraid that soldiers are waiting outside to kill them. The children's lives revolve around their family and their little home. When their houses and their small worlds are destroyed, they develop a sense of numbness, which is a characteristic symptom of PTSD.

Children are developing unrestrained anger directed towards Israelis. Their feelings of helplessness create more anger, and they are willing to use stones to fight against the Israeli soldiers. Children 10 to 12 years old recall how their friends threw stones at soldiers and how they were shot dead. The surviving children were angry, and even their parents could not help them in reducing the fear, anger, and feeling helpless.

Children 14-16 years old show more understanding. They verbalize the loss of their family, land, and homes, as well as the persistent humiliation they experience under foreign occupation. These children do not believe the reassurance given by elders that one day Palestine will become an independent state. They see only suffering, pain, and despair around them. They believe that they have nothing to look forward to except for misery, humiliation, and terror. These feelings further cement their anger and suicidal thoughts. They think of retaliation without worrying about the consequences. Dr. Iyad Sarraj, a Palestinian psychiatrist in Gaza City, has watched the suicide bombings with growing alarm. Having grown up with the idea of suicide attacks, Palestinian children are equating death with "power" and are creating a new kind of culture and compensating for the powerlessness of their parents in the face of humiliation of Israeli occupation. Some suicide bombers had no connection with the militant Islamic groups such as Hamas and Islamic Jihad, and most of them did not go through the months of preparation repeatedly mentioned in Western media. These young adults die with the hope that giving their lives will give lives to others. The principle behind suicide bombing is that it is better to die in dignity rather than to live in humiliation and shame. ${ }^{30}$

\section{Conclusion}

Individuals who are exposed to serious psychological traumas and develop PTSD may have multiple comorbid illnesses and multiple medical and psychiatric problems including hypertension, bronchial asthma, and peptic ulcers. Substance abuse, anxiety, and depression are also common occurrences. These symptoms of comorbidity mask the diagnosis of PTSD. The incidence of suicide is also high in PTSD patients. In some cases, depression changes to anger, and a small number of these adolescents are prepared to die while killing for the sake of their country. They die with a hope that giving their lives will give lives to others. To prevent depression, despair, anger, and revenge, therapeutic intervention is necessary. With limited resources and insurmountable problems, this is a difficult, if not an impossible task.

Traumatized children should be screened for anxiety, depression, and behavioral problems. Parents should also be counseled regarding the range of normal, emotional, and behavioral reactions of children to terror and the symptoms children manifest. Individual and family counseling is strongly recommended to prevent severe consequences of psychological trauma.

Therapeutic interventions such as critical incident stress debriefings, prolonged exposure therapy (PET), emotional support and psychoeducation are beneficial in treating children exposed to trauma, and these techniques also prevent the subsequent development of PTSD. Many medications such as selective serotonin reuptake inhibitors (SSRIs), tricycylic antidepressants, and antianxiety medications have been used to treat PTSD. The American Academy of Child and Adolescent Psychiatry practice guidelines defer to the psychiatrist's judgment to determine the best pharmacological approach. ${ }^{31-35}$

The U.S. Department of Health and Human Services awarded $\$ 10$ million in grants for the treatment of children and adolescents who have experienced traumatic events after September 11, 2001. Fortunately, Israeli children exposed to traumatic stress have institutions and professional staff to help 
and treat them. The goal is to stabilize and prepare them to live a normal life.

Palestinian children with traumatic experiences live in the same environment of misery and suffering but with severely limited therapeutic intervention. Without some kind of assistance to Palestinian children and an end to the occupation, the suffering of Palestinian children and the cycle of violence are likely to continue.

\section{References}

1. American Academy of Pediatrics, Work Group On Disasters. Psychosocial Issues for Children and Families in Disasters: A Guide for the Primary Care Physicians. Washington, DC: United States Department of Health and Human Services, Substance Abuse and Mental Health Services Administration; 1995. Publication Number SMA953022. Also available on-line at http://mentalhealth.samhsa.gov/publications/allpu bs/SMA95-3022/default.asp.

2. Kraft D. Terrorism's Toll Traumatizing Children. Jewish Telegraphic Agency. May 28, 2004/Sivan 8 5764, Volume 56:36. Also available on-line at http://www.jewishaz.com/jewishnews/040528/terro rism.shtml.

3. Beauchesne MA, Kelley BR, Patsdaughter CA, et al. Attack on America: children's reactions and parents' responses. J Pediatr Health Care. 2002; 16:213-21.

4. Monsen RB. Children and terror. J. Pediatr Nurs. 2002;17:62-63

5. Heim C, Meinlschmidt G, Nemeroff CB. Neurobiology of early life stress and its relationship to PTSD. Psychiatric Annals. 2003;33:18-26.

6. Silva RR, Alpert M, Munoz DM, et al. Stress and vulnerability to posttraumatic stress disorder in children and adolescents. Am J Psychiatry. 2000;157(8):122935.

7. American Psychiatric Association. Diagnostic and Statistical Manual of Mental Disorders (DSM-IV-TR). Arlington, VA: American Psychiatric Publishing; 2000. 8. Kubetin SK. Changes to the brain's structure are a hallmark of posttraumatic stress disorder. Clinical Psychiatry News. 2003 Jan;31(1):40. Also available at h t t p : / / w w w . cli n i c a l p s y c h i a trynews.com/article/PIIS0270664403700411/fulltext. 9. De Bellis MD, Keshavan MS, Clark DB, et al. A.E. Bennett Research Award. Developmental traumatology. Part I: Biological stress systems. Biol Psychiatry. 1999;45:1259-70.
10. De Bellis MD, Keshavan MS, Clark DB, et al. A.E. Bennett Research Award. Developmental traumatology. Part II: Brain development. Biol Psychiatry 1999; 45:1271-84.

11. Carrion VG, Weems CF, Ray RD, et al. Diurnal salivary cortisol in pediatric posttraumatic stress disorder. Biol Psychiatry. 2002;51: 575-82.

12. Heim C, Nemeroff CB. Neurobiology of early life stress: clinical studies. Semin Clin Neuropsychiatry. 2002;7:147-59.

13. Bremner JD, Narayan M, Staib LH, et al. Neural correlates of memories of childhood sexual abuse in women and without posttraumatic stress disorder. Am J Psychiatry. 1999 Nov;156(11):1787-95.

14. Medina J. Hippocompal volume and predicting PTSD. Psychiatr Times. 2003;20(2):8-11.

15. Weller EB, Shlewiet BK, Weller RA. Traumatized children: why victims of violence live out their nightmares. Current Psychiatry. 2003;2:30-40.

16. American Academy of Child and Adolescent Psychiatry. Practice parameters for the assessment and treatment of children and adolescents with posttraumatic stress disorder. J Am Acad Child Adolesc Psychiatry. 1998;37(10 supp):4S-26S.

17. Scheeringa MS, Zeanah Ch, Drell MJ, et al. Two approaches to the diagnosis of posttraumatic stress disorder in infancy and early childhood. J Am Acad Child Adoles Psychiatry. 1995;34:191-200.

18. Hagan JF Jr; American Academy of Pediatrics Committee on Psychosocial Aspects of Child and Family Health; Task Force on Terrorism. Psychosocial implications of disaster or terrorism on children: a guide for the pediatrician. Pediatrics. 2005;116:78795.

19. Schonfeld DJ. Supporting adolescents in times of national crisis: potential roles for adolescent health care providers. J Adolesc Health. 2002;30:302-7.

20. Pine DS, Cohen JA. Trauma in children and adolescents: risk and treatment of psychiatric sequelae. Biol Psychiatry. 2002;51:519-31.

21. Veenema TG, Schroeder-Bruce K. The aftermath of violence: children, disaster, and posttraumatic stress disorder. J Pediatr Health Care. 2002;16:235-44. 22. Swick SD, Jellinek MS, Dechant E, et al. Children of victims of September 11th: a perspective on the emotional and developmental challenges they face and how to help meet them. J Dev Behav Pediatr. 2002;23:378-84.

23. Fredrick CJ. Children Traumatized by Catastrophic situations. In Eth S, Pynoos RS, editors. Post 
Traumatic Stress Disorder in Children. Washington, DC: American Psychology Association Press; 1985. p. 71-100.

24. Foy DW, Madvig BT, Pynoos RS, et al. Etiologic factors in the development of posttraumatic stress disorder in children and adolescents. J Sch Psychol. 1996; 34:133-45.

25. Davidson JR, Hughes D, Blazer DG, et al. Post-traumatic stress disorder in the community: an epidemiological study. Psychol Med. 1991;21(3):713-721.

26. Portney C. Intergenerational Transmission of Trauma. Psychiatric Times. 2003;20:4. Also available at http://www.psychiatrictimes.com/p030438.html.

27. Husain SA. Hope for the children: Lessons from Bosnia. Columbia, MO and Tuzla, Bosnia and Herzegovina: International Medical and Educational Trust (IMET) and Behram and Begova Medresa; 1996. 28. Kelly PA, Lavery TF. Terror-related stress: how ready are you to deal with it? Current psychiatry. 2002;1:29-39. Also available from https://www.currentpsychiatry.com/pdf/0101/0101 _Terrorstress.pdf.

29. Grinfield MJ. National trauma: what are the consequences of war in the Middle East. Psychiatric Times. 2003;20. Also available from http://www.psychiatrictimes.com/p031001b.html. 30. NPR.org. [homepage on the Internet]. Profile: Mood of Palestinians in the Fifth Year of the Current Intifada. Washington, D.C.; National Public Radio. [updated October 14, 2004; cited January 27, 2007]. Available from http://www.npr.org/programs/atc/ transcripts/2004/oct/041014.mccarthy.html

31. Friedman MJ, Donnelly CL, Mellman TA. Pharmacotherapy of PTSD. Psychiatric Annals. 2003;33:57-62.

32. Friedman MJ, Davidson JRT, Mellman TA, et al. Guidelines for Pharmacotherapy and position paper on practice guidelines. In: Foa EB, Keane TM, Friedman MJ, editors. Effective treatments for PTSD: practice guidelines from the International Society for Traumatic Stress Studies. New York, NY: The Guilford Press; 2000:84-105.

33. March JS, Amaya-Jackson L, Murray MC, et al. Cognitive-behavioral psychotherapy for children and adolescents with posttraumatic stress disorder after a single-incident stressor. J Am Acad Child Adolesc Psychiatry. 1998;37:585-93.

34. Bisson JI. Early interventions following traumatic events. Psychiatric Ann. 2003;33:37-44.

35. Foa EB, Dancu CV, Hembree EA, et al. A comparison of exposure therapy, stress inoculation training, and their combination for reducing posttraumatic

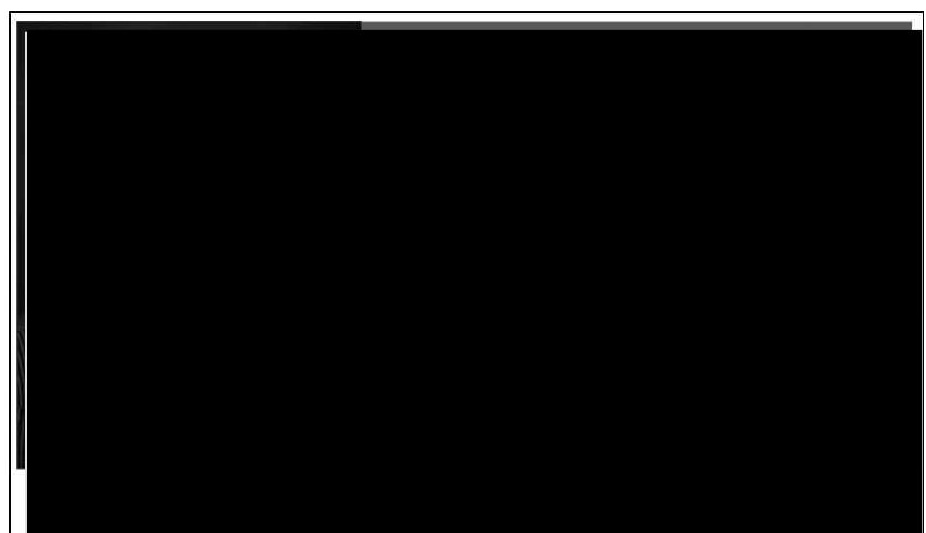

